2017-04-01

\title{
A simplified model for TIG-dressing numerical simulation
}

\author{
Ferro, $\mathrm{P}$
}

http://hdl.handle.net/10026.1/8759

10.1088/1361-651X/aa623d

Modelling and Simulation in Materials Science and Engineering

All content in PEARL is protected by copyright law. Author manuscripts are made available in accordance with publisher policies. Please cite only the published version using the details provided on the item record or document. In the absence of an open licence (e.g. Creative Commons), permissions for further reuse of content should be sought from the publisher or author. 


\section{A simplified model for TIG-dressing numerical simulation}

P. Ferro ${ }^{1}$, F. Berto ${ }^{2}$ and M. N. James ${ }^{3,4}$

${ }^{1}$ Department of Engineering and Management, University of Padova, Stradella San Nicola 3, 36100 Vicenza, Italy

${ }^{2}$ NTNU, Department of Engineering Design and Materials, Richard Birkelands vei 2b, 7491, Trondheim, Norway

${ }^{3}$ School of Engineering, University of Plymouth, Drake Circus, Plymouth, PL4 8AA, England ${ }^{4}$ Department of Mechanical Engineering, Nelson Mandela Metropolitan University, Port Elizabeth, South Africa

Corresponding author: Paolo Ferro

E-mail: ferro@gest.unipd.it

Pobile Phone. +39 334. 6957226

Phone: +39.0444.998727 - Fax: +39.0444.998884

Formatted: English (United Kingdom)

\section{Abstract}

Irrespective of the mechanical properties of the alloy to be welded, the fatigue strength of welded joints is primarily controlled by the stress concentration associated with the weld toe or weld root. In order to reduce the effects of such notch defects in welds, which are influenced by tensile properties of the alloy, post-weld improvement techniques have been developed. The two most commonly used techniques are weld toe grinding and TIG dressing, which are intended to both remove toe defects such as non-metallic intrusions and to re-profile the weld toe region to give a lower stress concentration. In the case of TIG dressing the weld toe is re-melted to provide a smoother transition between the plate and the weld crown and to beneficially modify the residual stress redistribution. Assessing the changes to weld stress state arising from TIG-dressing is most easily accomplished through a complex numerical simulation that requires coupled thermo-fluid dynamics and solid mechanics. However, this can be expensive in terms of computational cost and time needed to reach a solution. The present paper therefore proposes a simplified numerical model that overcomes such drawbacks and which simulates the remelted toe region by means of the activation and deactivation of elements in the numerical model.

Keywords: TIG dressing; weld residual stress; Finite element analysis; Notch stress intensity factor. 


\section{Introduction}

Welds contain macroscopic geometrical discontinuities as well as sharp micro-notches, such as weld toe intrusions. These stress concentrating features associated with the weld toe region act to reduce the fatigue strength of the weld and fatigue design codes therefore assume that life is dominated by crack growth. This assumption then further implies that there is little effect of alloy grade (strength level) on the observed fatigue life. As a result, the fatigue strength of different steel grades is usually assumed to be equal in design codes. It is possible, however, to improve the fatigue strength through the use of weld improvement techniques intended to produce compressive residual stress in the weld toe region and/or to reduce the local weld toe stress concentration through radiusing. Kirkhope et al. [1] provide a useful review of weld detail fatigue life improvement techniques and provide a summary diagram showing the various weld geometry improvement techniques and the methods that modify the residual stress field at the weld toe. Such techniques include various forms of peening (e.g. shot, laser and ultrasonic methods), and overloading (plastic deformation) methods, while weld geometry improvement techniques include grinding and remelting methods.

Weld toe grinding, hammer peening and TIG dressing are the most widely used methods in industrial applications. TIG dressing, in particular, is one of the most simplesimplest and most effective techniques to improve the fatigue strength of welds because it gives large improvements in fatigue performance, is inexpensive and low noise [1].

According to IIW recommendations, the aim of TIG-dressing is 'to remove the weld toe flaws by remelting the material at the weld toe. It also aims to reduce the local stress concentration effect of the local weld toe profile by providing a smooth transition between the plate and the weld face' [2].

TIG-dressing therefore removes slag inclusions and weld toe undercuts while also beneficially modifying both the hardness and the residual stress distribution. van Es et al. [3] give a useful review of the effect of TIG dressing on weld toe geometry, which they characterised by weld toe angle, weld 
toe radius, weld height and undercut. They also discussed hardness measurements in the remelted fusion zone and heat-affected zone (HAZ) and generally observed an increase in hardness which would be beneficial to fatigue strength, except in the case of very high strength steel grades (yield strength > $700 \mathrm{MPa})$.

As noted by van Es et al. in a related paper, [4] TIG dressing affects weld toe radius, the residual stress state, the local microstructure and also reduces the occurrence of weld toe defects. The change in residual stress that accompanies a TIG-dressing operation is of primary interest in the goal of fatigue life improvement and Finite Element (FE) models are a useful tool in the pursuit of this goal. A number of numerical models have been reported in the literature that simulate the fusion welding operation and the development of residual stresses [e.g. 5-9]. Numerical modelling has become increasingly important in recent years because computational modelling can aid in understanding the underlying mechanisms of welding, as well as in assessing the relative importance of various physical processes and predicting how different parameters can affect the final mechanical and metallurgical properties of the weld.

Most of these endeavours use 2D or 3D finite element analyses with thermo-elastic-plastic constitutive equations and compare the residual stress with limited (usually) experimental data. The more innovative smoothed particle hydrodynamics ( $\mathrm{SPH})$ technique was used by Das and Cleary in their 3D work [9]. SPH is a mesh-free numerical technique that has been developed for, and previously applied to, modelling of solid deformation problems for a range of applications [9]. It uses local interpolations on neighbouring discrete particles that are used to construct continuous approximations of a field. According to Das and Cleary [9], SPH offers many advantages for welding applications, such as the ability to follow very high deformations (beyond what is possible with meshbased methods) and to keep track of the history of the thermo-mechanical states of each part of the material. They state that this facilitates easy implementation of non-linear constitutive behaviours, e.g. rate dependent plasticity and viscoelasticity. Their work indicated that the spatial variation of 
the residual stress depended on the local temperature gradients and the resistance against thermal expansion, which is consistent with observations of arc welding processes.

In contrast to the significant body of published work that deals with modelling of residual stresses for arc welding generally, and TIG welding in particular [10], a much smaller number of papers have been published that deal with modelling and simulation of TIG-dressing [4, 11-13]. All numerical models make certain simplifying assumptions, usually related to the plastic deformation and constitutive behaviour, and very few consider a coupled analysis of thermo-fluid dynamics and mechanical influences. Martinez et al. [10] used a 3D finite element model that used linear elasticity to obtain the initial elastic stress field and then assumed elastic perfectly-plastic (EPP) constitutive behaviour to model the redistribution of residual stresses under fatigue loading. Their model also included the change in weld toe stress concentration arising from TIG-dressing. They compared their predictions with surface X-ray and neutron diffraction measurements and obtained a 'good', though unquantified, agreement between numerical and experimental data. More recent work by van Es et al. [4] used a critical distance approach in their modelling of notch stress to obtain a notch fatigue factor and a predicted fatigue life for TIG-dressed steel specimens. Residual stresses were included through the use of a mean stress factor. However, the data that they presented in their paper showed a large discrepancy between the predictions and their experimental data.

Although SPH techniques may be a good long term route to better modelling of weld residual stresses, there is still a significant need for, and challenge in, developing simplified models that can more accurately predict the weld stress state arising from TIG-remelting and hence lead to better fatigue life prediction. The present paper therefore proposes a simple notch stress intensity factor model in which the geometrical variation of the weld toe region due to the TIG-remelting effect is taken into account by means of the activation-deactivation of elements in the model. The concept of activation and deactivation onf elements in the context of new fast techniques for coupled numerical analysis of residual stresses in additive manufacturing is described in reference [14]. At the beginning of 
welding, all elements representing the weld zone are deactivated and therefore cannot physically interact with other elements. As the heat source starts to move, the elements are progressively activated. In this work, the activation-deactivation onf elements is used to simulate the effect of TIG-

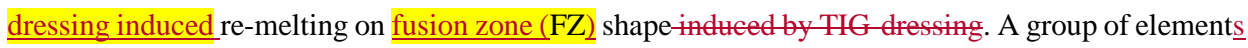
is created which model the variation of FZ shape. Such This group is deactivated during the TIG welding simulation and then activated when the arc welding source passes through the modelledcross _section being modelled during the TIG-dressing simulation.

\section{Notch effects in welds}

$\underline{\text { Reported }} M$ measurements of the weld toe radius for as-welded joints indicate that it has a verylow value ( $\rho=1-1.5 \mathrm{~mm}[15])$, even before account is taken of any intrusions or sharp undercut that may be present, and hence crack initiation by fatigue can be considered as a local phenomenon in which the high stress concentration ahead the weld toe plays a role of primary importance. In numerical modelling of the weld toe region, where the effect of intrusions and undercut must be included, it is

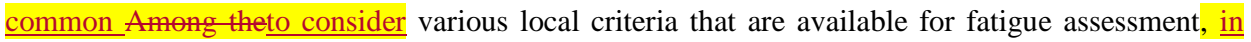
which the notch stress intensity approach models the weld toe region as a pointed V-notch of zero notch root radius. Accordingly, the intensity of the singular stress distribution in this critical weld region can be quantified by means of Notch Stress Intensity Factor (NSIF) which has been proven to be an capable of summarising the high cycle fatigue strength of welded joints having very different global and local geometries [16].

Under the assumption of linear-elastic plane-stress or plane-strain conditions, the analytical expression for the stress field in the vicinity of the tip of a sharp V-notch was given by Williams, for both Mode I and Mode II loading [17]. Employing only the first term of the Williams' expansion series in Mode I loading of the V-notch, the stress field around the notch tip (Fig. 1) can be described by the following equation (1): 


$$
(r, \quad)=\frac{K_{I}^{N}}{r^{1}{ }_{I}} f_{i j}^{I}() \quad(i, j=r, \quad)
$$

where $f_{i j}(\theta)$ are the angular functions (which have closed form expressions [18]), $\lambda$ is the first eigenvalue obtained from Eq. (2),

$$
\sin (2)+\sin (2 \quad)=0
$$

and $K_{I} N$ is the NSIF due to a thermal or mechanical symmetrical load (opening Mode I) that is calculated according to the Gross and Mendelson definition [19]:

$$
K_{I}^{N}=\sqrt{2} \lim _{r \rightarrow 0} r^{1}{ }^{I} \quad(r, \quad=0)
$$

The first eigenvalue depends only by the V-notch angle $(2 \alpha)$ and varies in a range between 0.5 (when $2 \alpha=0$ ) and 0.757 (when $2 \alpha=5 \pi / 6)$ [18] so that Eq. (1) contains a singular term $\left(r^{\prime}{ }^{1}\right.$ when $\mathrm{r} \rightarrow 0$ ).

After TIG-dressing a significant improvement in weld toe radius is achieved as demonstrated in Fig. 2, so that the NSIF parameter can no longer be used. In this case, the stress that governs the fatigue behavior is averaged over a small characteristic length or volume, unique to the alloy under consideration. Using this concept, several different models have been proposed, including the critical distance model [20], the stress averaging method [21-23], the stress gradient approach [24] and the highly stressed volume technique [25].

\section{Model description}

Fillet welding was simulated using the numerical Sysweld ${ }^{\circledR}$ code in a 2D model, in - In-order to drasticallyboth reduce the computational cost needed to reach the $\underline{\text { a }}$ solution, $\underline{\text { and }}$ as part of the stated
Formatted: English (United Kingdom)

Formatted: English (United Kingdom)

Formatted: English (United Kingdom)

\begin{tabular}{|l|}
\hline Formatted: English (United Kingdom) \\
\hline Formatted: English (United Kingdom) \\
\hline Formatted: English (United Kingdom) \\
\hline Formatted: English (United Kingdom) \\
\hline Formatted: English (United Kingdom) \\
\hline Formatted: English (United Kingdom) \\
\hline Formatted: English (United Kingdom) \\
\hline Formatted: English (United Kingdom) \\
\hline Formatted: English (United Kingdom) \\
\hline
\end{tabular}


desire to pursue a simple but more accurate modela $2 \mathrm{D}$ model was used. The thickness of the tee-Tjoint plates was modelled as $6 \mathrm{~mm}$ while the bead throat and legs were made equal to $2.5 \mathrm{~mm}$ and 3.5 $\mathrm{mm}$, respectively. The weld toe of the as-welded joint was modelled as a sharp, zero radius, V-shaped notch with an opening angle $(2 \alpha)$ equal to $135^{\circ}$ (Fig. 3).

After TIG-dressing, measurements of the weld toe radius indicate typical radii of around $5 \mathrm{~mm}$ (Fig. 2). In order to simulate this geometric effect induced by the PWHT, a group of elements (named TD) was created that modifies the geometry of the as-welded joint at the weld toe region (Fig. 4) (assuming that there is no undercut). That group of elements is deactivated during the welding operation, and is subsequently activated at the point in the analysis that corresponds with remelting of the toe region. It should be noted that Fig. 4 appears to indicate that metal is added during the TIG-dressing process whereas in this work use of the TD mesh it is an assumption used to model the change in geometry at the weld toe. This is not a limitation as during TIG-dressing a group of elements could be also deactivated in order to preserve mass conservation.; The activation/deactivation SYSWELD option for elements was also used during modelling of welding process in order to simulate deposition of filler metal. The molten-remolten effect was simulated by incorporating a function that clears the history of an element once the temperature exceeds the melting temperature, which was taken as $1,500^{\circ} \mathrm{C}$

Both the parent metal (PP) and the filler metal were modelled as carbon steel whose chemical composition matched that of the Standard ASTM SA 516 Grade 65 (see Table 1).

Radiative heat loss (using the Stephan-Boltzmann law) and convective heat loss (using a convective heat transfer coefficient equal to $25 \mathrm{~W} / \mathrm{m}^{2} \mathrm{~K}$ ) were applied at the boundary (external surfaces) of the plates to be joined. Thermo-metallurgical and mechanical properties as a function of metallurgical phase and temperature were taken from the Sysweld Toolbox 2011® [26].

The influence of phase changes during welding should not be underestimated; Bhadeshia [27] has emphasised the important role that metallurgical phase transformations and associated shape changes 
play in affecting the development of residual stresses. He outlined the design of alloys such that the deformation caused by bainite and martensite transformations can eliminate residual stress, leading to extraordinary improvements in the fatigue life of constrained structural assemblies. It is clearly highly beneficial to optimally design welding fabrication in terms of both process parameters, e.g. heat input, preheat and interpass temperatures, as well as in metallurgical terms through consideration of filler metal alloy content, cooling rate and post-weld heat treatment (PWHT).

In including metallurgical effects in the present analysis the following phases were considered: martensite, bainite, ferrite-pearlite, tempered martensite, tempered bainite and austenite. The simplifying assumptions were made that tempered bainite has the same properties as ferrite and that tempered martensite is similar in properties to bainite. The metallurgical transformations primarily depend on thermal history with this dependence described through continuous cooling transformation (CCT) diagrams, which plot the start and end transformation temperatures as a function of cooling rate or cooling time. In the present work the diffusion-controlled phase transformations and the displacive martensitic transformation are modeled by means of the Leblond-Devaux kinetic law [28] and the Koistinen-Marburger law [29], respectively. Fig. 5 shows the CCT diagram that was followutilised in this work.

The heat source was modelled using a double ellipsoid power density distribution function given by Goldak et al. [30] (Eq. 4) that has been used previously in published literature for arc welding simulation [31].

$$
q_{g}(x, y, t)=\frac{6 \sqrt{3} f_{1,2} Q}{\sqrt{ } a b c_{1,2}} e^{\frac{3 x^{2}}{a^{2}}} e^{\frac{3 y^{2}}{b^{2}}} e^{\frac{3[v(t)]^{2}}{c_{1,2}^{2}}}
$$

The meaning of the symbols in Eq. (4) and their values are summarized in Tables 2 and 3. 
Introduction of a moving thermal source in the computational model requires a local coordinate system to be created, where the amount of thermal energy flow into the material depends upon the distance from the centre of welding. It is worth noting that the local coordinate system was rotated by $\beta=15^{\circ}$ (Fig. 3) for both TIG welding and TIG-dressing.

By taking advantage of the double symmetry, one half of the joint could be modelled and analysed using approximately 4617 linear isoparametric elements (Fig. 4). At the notch tip, the minimum size of the elements was about $5 \times 10^{-4} \mathrm{~mm}$. Finally, an uncoupled, thermomechanical analysis was carried out under generalized plain strain conditions- with the application of an fisostatic constraint condition was applied.

\section{Results and discussion}

\subsection{Thermo-metallurgical results}

Fig. 6 shows the temperature distribution at the point when the fusion zone has its maximum width with the fusion zone (FZ) being shown in red. Fig. 7 shows the proportional distribution of phases after cooling. The colour bar indicates the extent of the various volume fractions of the indicated phase after the initial welding run (left) and after subsequent TIG dressing of the weld toe (right). The interpass temperature was maintained at approximately room temperature. As indicated in Fig. 7, for both after either TIG welding andor TIG-dressing the room temperature microstructure primarily comprisespredominantly comprises -a mixture of ferrite-pearlite and bainite. Bainite forms the most prevalent phase in the FZ and HAZ in accordance with the CCT diagram. However, TIGdressing induceds the formation of martensite in the re-melted region near the weld toe. FThis occurs because the large mass of unmelted material that surrounds the herelatively small FZ induced during TIG-dressing, acts as a heat sink and experiencesleads to a highfast cooling rate that exceedsexceeds the critical quenching cooling rate for the transition to martensite, because of the surrounding large mass of unmelted material which acts as a heat sink. It is worth noting that, as expected, only a smallittle difference is observed in the bainite proportion between the as-welded and the heat treated 
(TIG-dressed) transformation temperature A1.

\subsection{Residual stress}

After welding the resdualresidual stress distribution was found to be positive and highly concentrated at the notch tip (Fig. 8a); on the other hand, however, after TIG-dressing; residual stresses were negtivenegative and well distrubuteddistributed in a wider zone aheadround the weld toe (Fig. 8b).

The residual stress distribution along the notch bisector $(\theta=0)$ near the weld toe that is induced by TIG-dressing is shown in Fig. 9. In that figure the residual stress is plotted in the using polar coordinates system-that is -are generally used to describe the analytical stress distribution in blunt notches [32]. It can be observed that the residualstress distribution-values of both $\sigma_{\theta \theta}$ and $\sigma_{\text {II }}$ wasere found to be negative. As a matter of factThis arises because the austenitic to martensitic transformation in the weld toe region (Fig. 7) aceursoccurs with a specific volume increment which depends on the carbon percentage dissolved in austenite. Such volume increment is also greathergreater than that induced by the surraundingsurrounding austenitie to bainitice or ferritice transformation. During cooling, the specific volume increment of the weld toe region that experienced the phase transformation contrasts with the thermal shrinkage of the un-tranformedtransformed zone resulting in a compressive residual stress near the weld toe. Furthermore, because of geometrical smoothing of the weld toe region resulting from the remelting, the stress concentration is greatly reduced (Fig. 9). According to the predicted residual stress ditributiondistribution obtained from the numerical model induced by of TIG-dressing and predicted by the model, shows that an improvement efin fatigue strength of the heat treated joint is aspectedexpected compared to that of the as-welded joint, as proved-demonstrated by experiments [33].

\section{Conclusions}

Commented [MNJ3]: I think that we should include an additional figure called Fig. 9a that shows the residual stress distribution in the as-welded state. The current Fig. 9 then becomes Fig. $9 \mathrm{~b}$. 
The work presented in this paper demonstrates a substantial reduction in the complexity and computational effort of a coupled thermo-fluid dynamics and mechanical analysis of welds benefit substantially fromvia the exploitation of novel simplified 2D numerical models that uses element activation-deactivation to simulate the weld toe geometrical change induced by remelting [14]. The present paper has proposed such a model for the TIG-dressing process in which all metallurgical and mechanical phenomena (including transformation-induced plasticity) were taken into account in the residual stress computational process. The main results obtained in this work can be summarised as follows:

1) TIG-dressing promotes thean austenitice to martensitice transformation in the remelted region; this transformation dependswill be a function of -on the alloy chemical composition and the welding process parameters. Due to its specific volume increment, the austenitice to martensitice transformation induces compressive residual stress near the weld toe region resultingthat provides an improvement -in a fatigue strength improvement-of the joint.

1) 2) The stress distribution at the weld toe of the as-welded joint was found to be positive (tensile stress) and highly concentrated at the notch tip.

2) 3) In contrast, Tthe residual stress redistribution induced through TIG-dressing is not observed to be singular and is changed from tensile in nature to compressive. These changes arise from a combination of geometrical smoothing of the weld toe region, i.e. a $\underline{\text { reduction in local stress concentration, }}$ and the austenite to martensite transformation induced during the remelting process_which induces compressive residual stresses from 
the associated volume expansion. These observations underpin and explain the significant improvement in fatigue life arising from TIG-dressing, as indicated in reference 33.

\section{References}

[1] Kirkhope KJ, Bell R, Caron L, Basu RI and. Ma K-T. Weld detail fatigue life improvement techniques. Part 1: review. Marine Structures 1999;12;447-474.

[2] Haagensen PJ and Maddox SJ. IIW recommendations on post weld improvement of steel and aluminium structures. IIW Commission XIII, July 2001.

[3] van Es SHJ, Kolostein MH, Pijpers RJM, Bijlaard FSK. TIG-dressing of high strength steel butt welded connections - Part 1: weld toe geometry and local hardness. Procedia Engineering 2013;66;216 - 225.

[4] van Es SHJ, Kolostein MH, Pijpers RJM, Bijlaard FSK. TIG-dressing of high strength steel butt welded connections - Part 2: physical modelling and testing. Procedia Engineering $2013 ; 66 ; 126-137$.

[5] Ferro P, Bonollo F, Tiziani A. Laser welding of copper-nickel alloys: a numerical and experimental analysis. Science and Technology of Welding and Joining, 2005;5(3);299-310.

[6] Ferro P, Porzner H, Tiziani A, Bonollo F. The influence of phase transformations on residual stresses induced by the welding process - 3D and 2D numerical models. Modelling Simul. Mater. Sci. Eng. 2006;14;117-136.

[7] Ferro P, Zambon A, Bonollo F. Investigation of electron beam welding in wrought Inconel 706 - experimental and numerical analysis. Materials Science and Engineering A. 2005;392;94-105.

[8] Akbari SAA and Miresmaeili R. Experimental and numerical analyses of residual stress distributions in TIG welding process for 304L stainless steel. Journal of Materials Processing Technology 2008;208;383-394. 
[9] Das R and Cleary PW. Three-dimensional modelling of coupled flow dynamics, heat transfer and residual stress generation in arc welding processes using the mesh-free SPH method. Journal of Computational Science 2016;16;200-216.

[10] Vemanaboina H, Akella S and Buddu RK. Welding process simulation model for temperature and residual stress analysis. Procedia Materials Science 2014;6;1539 - 1546.

[11] Lopez Martinez L, Lin Peng R, Blom AF and Wang DQ. Welding and TIG-dressing induced residual stresses - relaxation and influence on fatigue strength of spectrum loaded weldments. European Structural Integrity Society 1999;23;117-133.

[12] Hildebrand J, Starcevic I, Werner F, Heinemann H and Köhler G. Numerical simulation of TIG-dressing of welded joints. Joint International Conference on Computing and Decision Making in Civil and Building Engineering. June 14-16, 2006 - Montreal, Canada.

[13] Zhou K, Shi C, Jin C. Influence of cooling intensity on residual stress state of TIG-dressing zone for T-joint welded toe. Applied Mechanics and Materials 2012;148-149;1289-1294.

[14] Keller N and Ploshikhin V. New method for fast predictions of residual stress and distortion of AM parts. Proceedings of the $25^{\text {th }}$ International Solid Freeform Fabrication Symposium, Austin, Texas, 4-6 August 2014, pp 1229-1237.

[15] Pedersen MM, Mouritsen OØ, Hansen MR, Andersen JG. Experience with the Notch Stress Approach for Fatigue Assessment of Welded Joints, Swedish Conference on Light Weight Optimized Welded Structures, Borlänge, 2010

[16] Livieri P, Lazzarin P. Fatigue strength of steel and aluminium welded joints based on generalised stress intensity factors and local strain energy values. Int. J. Fract. 2005;133; $247-276$.

[17] Williams ML. Stress singularities resulting from various boundary conditions in angular corners of plates in extension. J Appl Mech 1952;19:526-28.

[18] Livieri P and Lazzarin P. Fatigue strength of steel and aluminium welded joints based on 
generalised stress intensity factors and local strain energy values. Int J Fract 2005;133:24776

[19] Gross R and Mendelson A. Plane elastoplastic analysis of V-notched plates. Int. J. Fract. Mech $1972 ; 8: 267-76$

[20] Peterson RE, Stress concentration factors, John Wiley, New York, 1974

[21] Neuber H, Kerbspannungslehre, Springer Verlag, 1937

[22] Neuber H, Theory of Notch Stresses, Ann Arbor Mich, 1946

[23] Neuber H, Über die Berücksichtigung der Spannungskonzentration bei Feistigkeitsberechnungen, Konstruktion, 1968;20(7);245-251,

[24] Siebel E, Stieler M, Ungleichförmiche Spannungsverteilung bei schwingender Beanspruchung, VDI-Zeitsschrift 1993;97(5);121- 126,

[25] Kuguel R. A relation between theoretical stress concentration factor and fatigue notch factor deduced from the concept of highly stressed volume, ASTM 61, 732-744, 1961

[26] Sysweld Toolbox 2011®

[27] Bhadeshia, H.K.D.H. Developments in martensitic and bainitic steels: role of the shape deformation, Materials Science and Engineering: A, 378 (2004) 34-39.

[28] Leblond JB and Devaux J. A new kinetic model for anisothermal metallurgical transformations in steels including the effect of austenite grain size. Acta Metall 1984;32:13746

[29] Koistinen DP and Marburger RE. A general equation prescribing extent of austenitemartensite transformation in pure iron-carbon alloys and carbon steels. Acta Metall $1959 ; 7: 59-68$

[30] Goldak J, Chakravarti A and Birbby M. A new finite element model for welding heat sources. Metallur Trans B 1984;15b:299-305.

[31] Ferro P, Bonollo F, Tiziani A. Methodologies and experimental validations of welding process 
numerical simulation. Int $\mathbf{J}$ Computational Materials Science and Surface Engineering 2010;3:114-32

[32] P. Lazzarin, S. Filippi. A generalized stress intensity factor to be applied to rounded V-shaped notches. International Journal of Solids and Structures 2006;43;2461-2478.

[33] Yildirim HC. Review of fatigue data for welds improved by tungsten inert gas dressing. International Journal of Fatigue 2015;79;36-45. 


\begin{tabular}{ccccccccccr}
\hline $\mathrm{C}$ & $\mathrm{Mn}$ & $\mathrm{Si}$ & $\mathrm{P}$ & $\mathrm{S}$ & $\mathrm{Cr}$ & $\mathrm{Ni}$ & $\mathrm{Cu}$ & $\mathrm{Cr}+\mathrm{Ni}+\mathrm{Cu}$ & $\mathrm{Nb}$ & $\mathrm{Al}_{\text {all }}$ \\
\hline max. & max. & max. & max. & max. & max. & max. & max. & max. & Min. \\
\hline 0.18 & 1.6 & 0.55 & 0.035 & 0.035 & 0.3 & 0.3 & 0.3 & 0.7 & $0.02-0.08$ & 0.015 \\
\hline+0.03 & +0.05 & +0.05 & +0.005 & +0.005 & \multicolumn{7}{c}{ Allowable variation } \\
\hline
\end{tabular}

Formatted: English (United Kingdom)

Table 1 - Chemical composition of the ASTM SA 516 alloy (wt $\%$ ).

\begin{tabular}{clc}
\hline $\mathrm{Q}^{*}$ & Power input $[\mathrm{W}]$ & $*$ \\
$\eta$ & Efficiency & 0.64 \\
$\mathrm{Q}$ & Absorbed power $[\mathrm{W}]$, with $\mathrm{Q}=\eta \mathrm{Q}^{*}$ & - \\
\hline $\mathrm{a}$ & & $*$ \\
$\mathrm{~b}$ & Molten pool dimensions, $[\mathrm{mm}]$ & $*$ \\
$\mathrm{c}_{1}$ & & 2.3 \\
$\mathrm{c}_{2}$ & & 7.9 \\
\hline $\mathrm{f}_{1}$ & \multirow{2}{*}{ Constants for the energy distribution of the heat flux } & 0.6 \\
$\mathrm{f}_{2}$ & & 1.4 \\
\hline $\mathrm{v}$ & Welding speed $\left[\mathrm{mms}^{-1}\right]$ & 11 \\
& Total duration of time before the welding source has traversed & $*$ \\
\hline & the transverse cross section of the plate [s] & \\
\hline
\end{tabular}

Table 2. Goldak's source parameters. * indicates that the value used depends on the process (see Table 3). The high value of $\tau$ for TIG-dressing includes the time necessary for the weld to cool to room temperature after welding.

\begin{tabular}{rcccc}
\hline & $\mathrm{Q}^{*}[\mathrm{~W}]$ & $\mathrm{a}[\mathrm{mm}]$ & $\mathrm{b}[\mathrm{mm}]$ & $\tau[\mathrm{s}]$ \\
\hline TIG welding & 7000 & 4 & 6 & 35 \\
\hline TIG-dressing & 1400 & 5 & 0.5 & 6038 \\
\hline
\end{tabular}

Formatted: English (United Kingdom)

Table 3 -Heat source parameters given as a function of the weld process. 


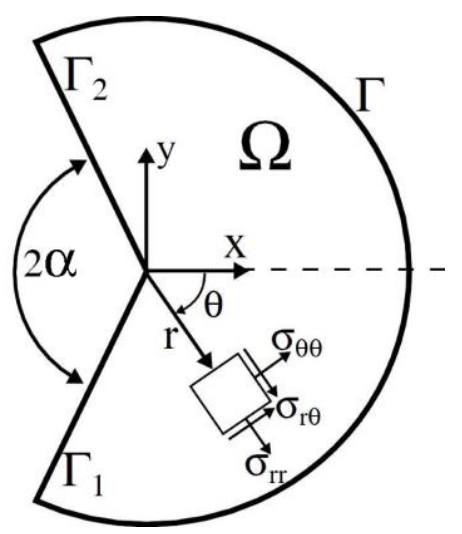

Fig. 1 - Domain $\Omega$ for the sharp V-notch problem.
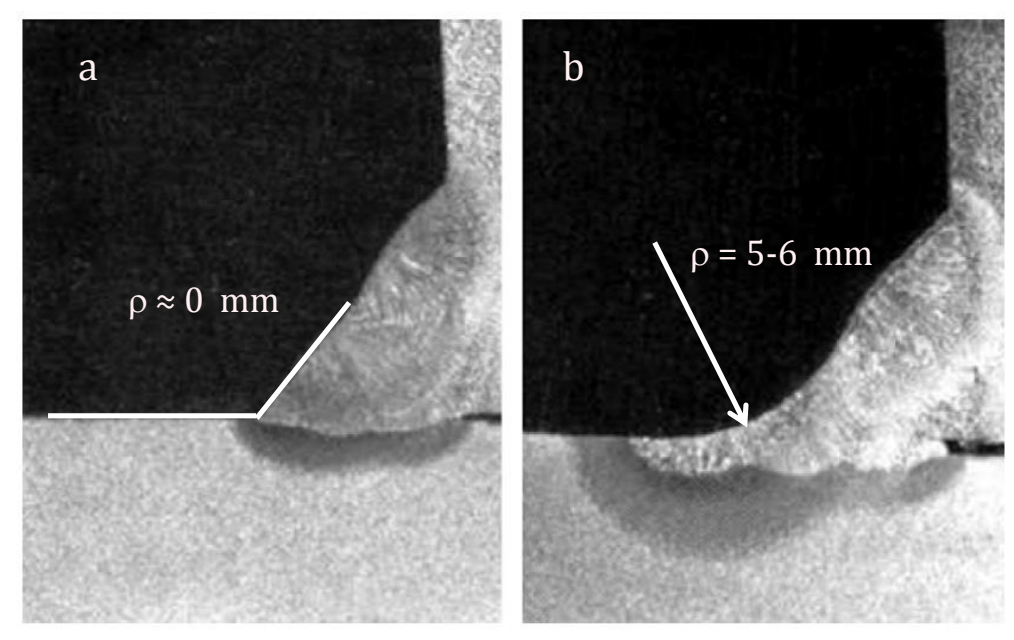

Fig. 2 - Fillet weld toe radius before (a) and after (b) the TIG-dressing process. 


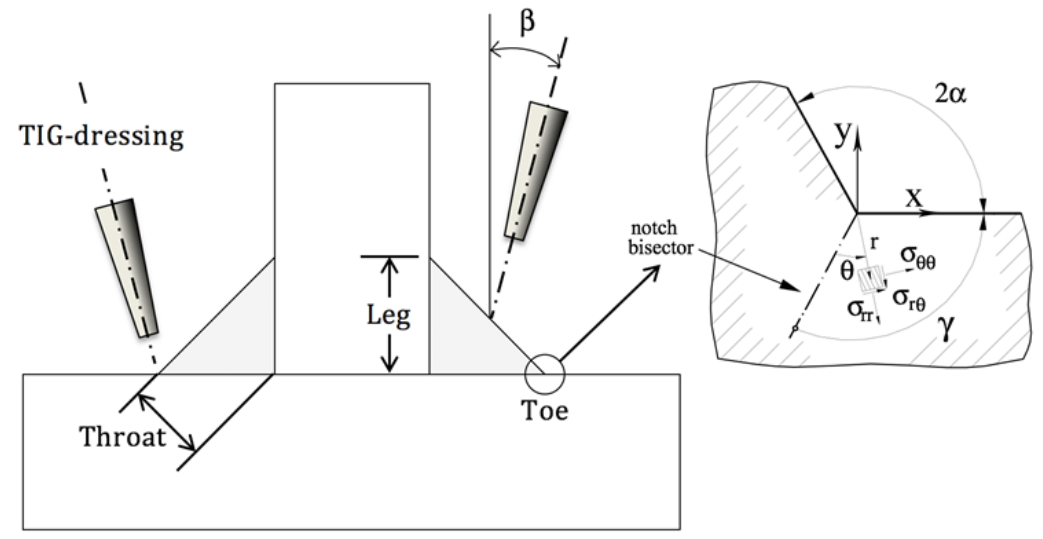

Fig. 3 -Schematic representation of the T-fillet welded joint analysed in this work and the corresponding cartesianCartesian and polar coordinate systems centred at the tip of the V-notch with opening angle $2 \alpha$ (the welding direction is along the $\mathrm{z}$ axis).

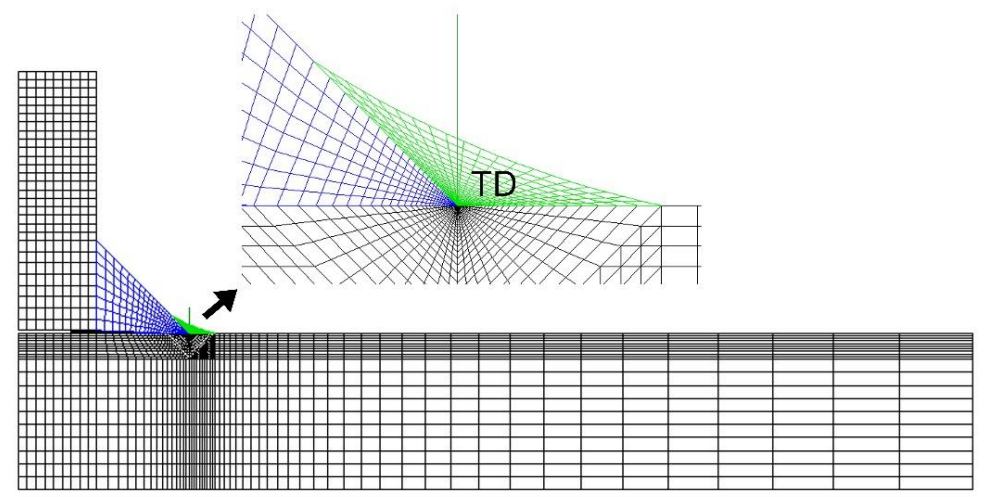

Fig. 4 -2D numerical model showing the element groups used to simulate the geometric effect arising in the TIG-dressing process (TD = TIG-dressing geometry effect). 


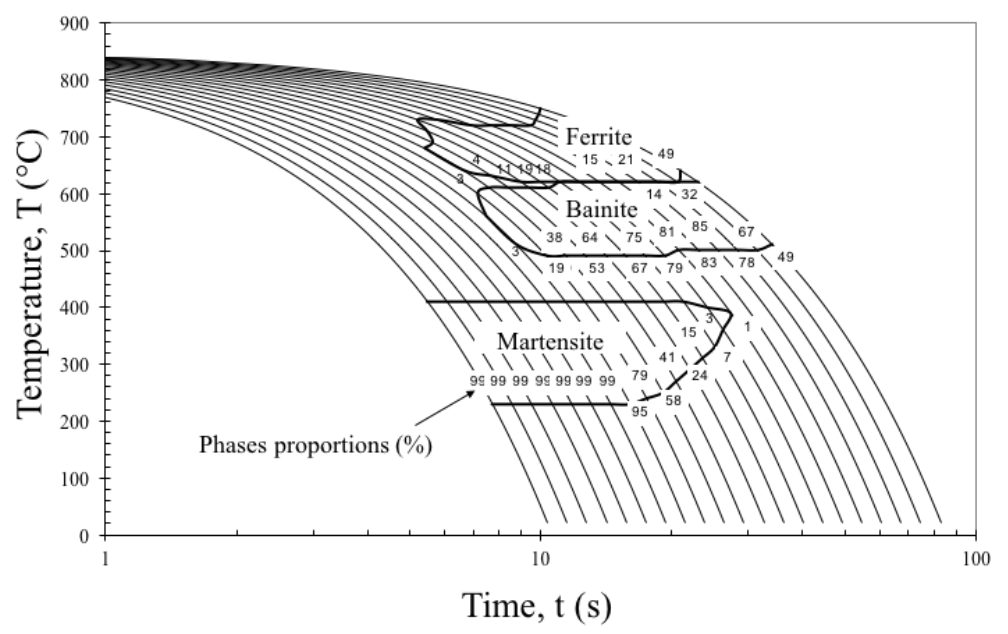

Fig. 5 - CCT diagram for the ASTM SA 516 alloy.

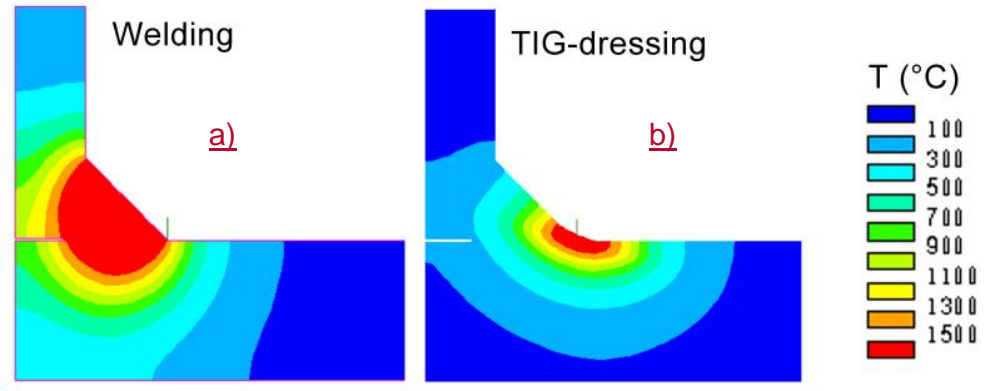

Fig. 6 - FZ shape induced during a) TIG welding and b) TIG-dressing respectively. 
Welding

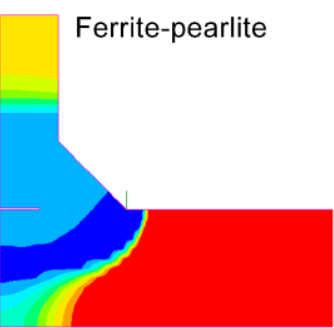

Bainite
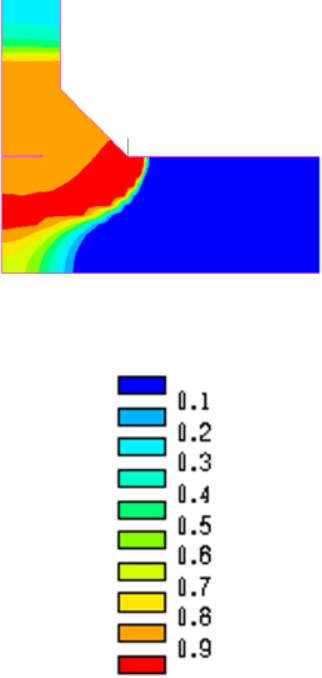

TIG-dressing

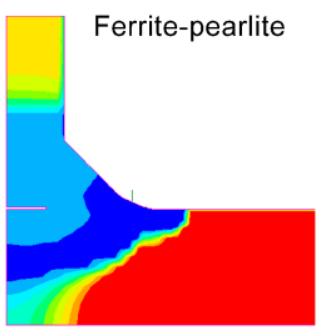

Bainite

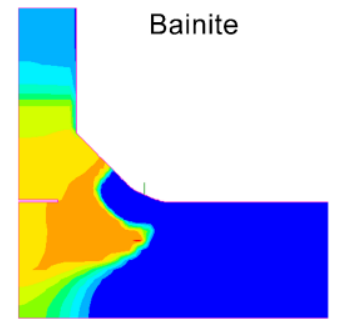

Martensite

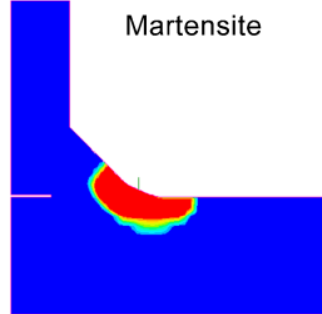

Fig. 7 - Metallurgical phase proportions present in the weld zone at ambient temperature: (left) after TIG welding and (right) after subsequent TIG-dressing. 

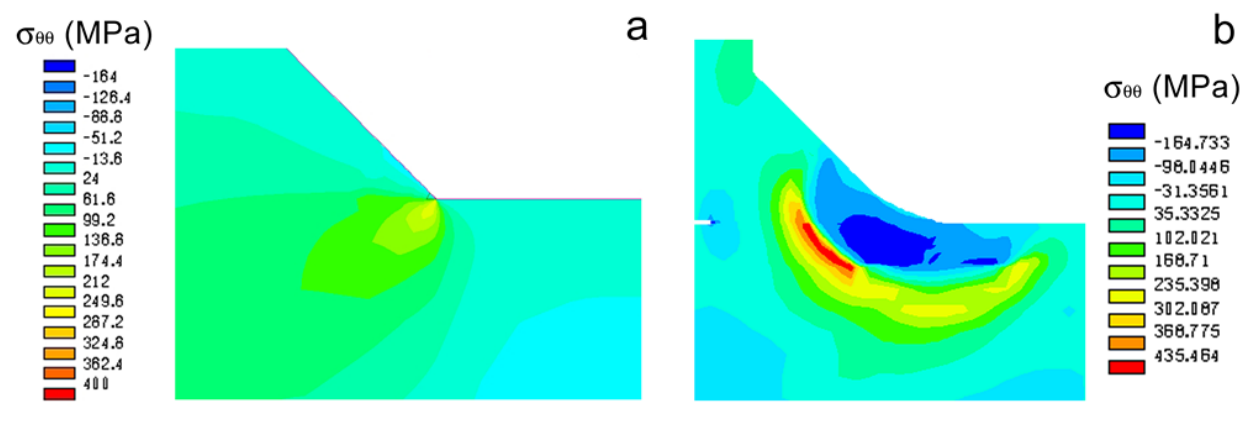

Fig. 8 - Predicted residual stress distribution after a) welding and b) TIG-dressing

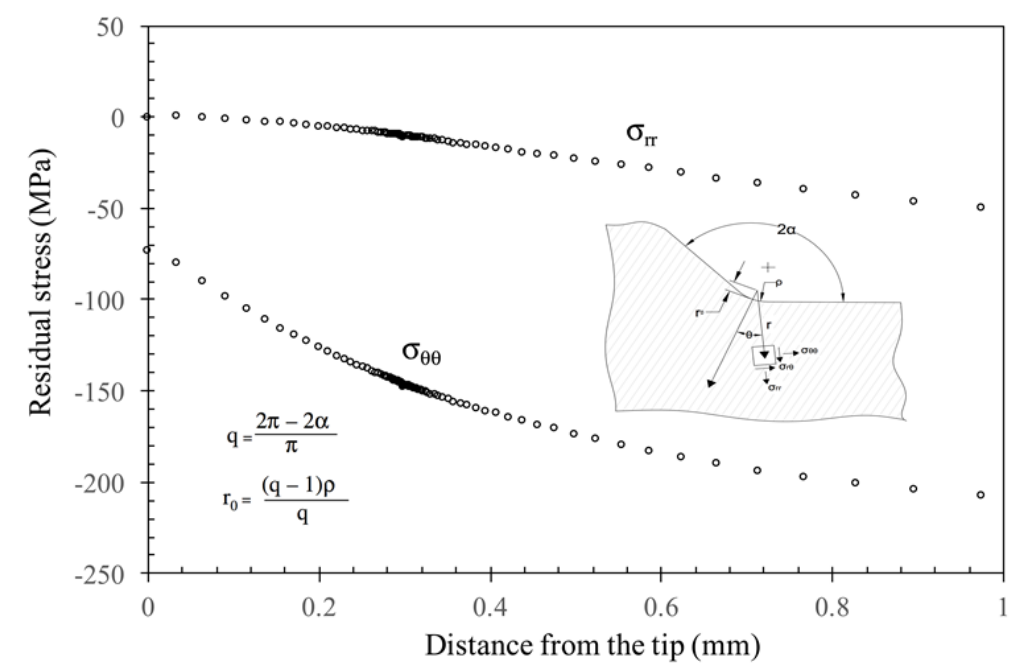

Fig. 9 - Residual stress distribution along the notch bisector $(\theta=0)$ near the weld toe after TIGdressing ( $\rho=5 \mathrm{~mm}, 2 \alpha=135^{\circ}$ ). 